\title{
A STUDY ON HYSTEROLAPAROSCOPY IN FEMALE INFERTILITY- A DIAGNOSTIC CUM THERAPEUTIC TOOL
}

\author{
Atal Bihari Dandapat', Sapneswar Behera², Swati Sucharita Sahoo ${ }^{3}$
}

${ }_{1}^{1}$ Associate Professor, Department of Obstetrics and Gynaecology, VSSIMSAR, Burla, Odisha, India.

${ }^{2}$ Senior Resident, Department of Obstetrics and Gynaecology, VSSIMSAR, Burla, Odisha, India.

3Postgraduate Student, Department of Obstetrics and Gynaecology, VSSIMSAR, Burla, Odisha, India.

\section{BACKGROUND}

ABSTRACT

Infertility, according to WHO, is defined as "a disease of the reproductive system defined by the failure to achieve a clinical pregnancy after 12 months or more of regular unprotected sexual intercourse." Infertility affects $10-15 \%$ of couples[1] posing a unique issue, as the couple must be treated rather than an individual.

To evaluate the role of hysterolaparoscopy in female infertility and to study the effect of therapeutic procedures in achieving fertility.

\section{MATERIALS AND METHODS}

Forty consenting subjects excluding male factor infertility with normal hormonal profile and no contraindication to laparoscopy were subjected to diagnostic hysteroscopy and laparoscopy.

Statistical Analysis Used: The data obtained from the medical records was categorised as patients with primary and secondary infertility and statistical analysis was done by using descriptive statistical method for determining frequencies and percentages and Chi-square test was used for determination of associations between categorical variables. A p-value of $\leq 0.05$ was regarded as statistically significant and software used in the analysis was SPSS 17.0 version.

Settings and Design: A prospective (Observational) study of forty patients with female infertility presenting to Outpatient Department of Obstetrics and Gynaecology, VIMSAR, Burla were evaluated over a period of 12 months.

\section{RESULTS}

We studied 40 patients comprising of $24(60 \%)$ cases of primary infertility and $16(40 \%)$ patients of secondary infertility. The average age of active married life for 40 patients was between 6 and 8 years. In our study, the most commonly found pathologies were PCOD, endometriosis and tubal blockage septate uterus. 13 (32.5\%) patients conceived after hysterolaparoscopy followed by artificial reproductive techniques.

\section{CONCLUSION}

This study demonstrates the benefit of laparohysteroscopy for diagnosis and as a therapeutic tool in patients with primary and secondary infertility. We were able to achieve a higher conception rate of $32.5 \%$.

\section{KEY WORDS}

Diagnostic cum Therapeutic Tool, Infertility, Hysterolaparoscopy, Artificial Reproductive Techniques.

HOW TO CITE THIS ARTICLE: Dandapat AB, Behera S, Sahoo SS. A study on hysterolaparoscopy in female infertility- a diagnostic cum therapeutic tool. J. Evolution Med. Dent. Sci. 2018;7(34):3750-3753, DOI: 10.14260/jemds/2018/842

\section{BACKGROUND}

Infertility, according to WHO, is defined as "a disease of the reproductive system defined by the failure to achieve a clinical pregnancy after 12 months or more of regular unprotected sexual intercourse." Infertility affects $10-15 \%$ of couples[1] posing a unique issue, as the couple must be treated rather than an individual. Of the causes of infertility, the female factor contributes in the majority of cases (40 $55 \%)$ followed by the male factor $(30-40 \%)$, both partners $10 \%$ and unexplained (10\%) in the remainder. Clinically, the majority of pelvic pathologies have been difficult to determine based on routine pelvic examinations alone.

'Financial or Other Competing Interest': None.

Submission 09-07-2018, Peer Review 02-08-2018,

Acceptance 09-08-2018, Published 20-08-2018.

Corresponding Author:

Dr. Sapneswar Behera,

C/o. Dr. Atal Bihari Dandapat,

Quarter No. C/3, Near SBI Burla Post,

Burla Distr., Sambalpur-768017, Odisha, India.

E-mail: beherasapneswar@gmail.com

DOI: $10.14260 /$ jemds $/ 2018 / 842$

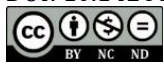

The ability to see and manipulate uterus, fallopian tubes and ovaries during laparoscopy has made it an essential part of infertility evaluation. Similarly, visualising the uterine cavity and identifying the possible pathology has made hysteroscopy[1] an equally important tool in infertility evaluation. The question of tubal morphology, tubal patency, ovarian morphology, unsuspected pelvic pathology and uterine cavity abnormalities can all be resolved with accuracy at one session by using a combined hysterolaparoscopy. In addition, hysterolaparoscopy-guided biopsy and therapeutic procedures such as ovarian drilling, myomectomy, septal resection and adhesiolysis can be done in the same setting.

Currently, the gold standard of diagnosis and treatment of infertility is hysteroscopy and laparoscopy. Our study was undertaken to find the hysterolaparoscopic findings in 40 infertile women, which would help in planning appropriate management in our setting.

\section{MATERIALS AND METHODS}

This prospective (observational) study of forty patients with female infertility presenting to Outpatient Department of Obstetrics and Gynaecology, VIMSAR, Burla were evaluated 
over a period of 12 months. All women who failed to conceive after 12 months of regular intercourse were included.

A complete and relevant history and clinical examination was carried out. A complete hormonal profile including serum follicle stimulating hormone, luteinizing hormone, prolactin, progesterone and thyroid stimulating hormone was performed in all patients. Forty consenting subjects with normal hormonal profile and no contraindication to the procedure were included in this study. The sample size was calculated as patients completing follow-up of 1 year since the start of the study.

During the laparohysteroscopic procedure the pelvis was inspected including uterus, fallopian tube, round ligaments, uterovesical pouch, uterosacral ligaments and Pouch of Douglas. The tubes were inspected for any abnormality in their length and shape. Both ovaries were inspected regarding their size, shape, thickness of peripheral follicles, evidence of ovulation and their relationship with fimbrial end of tubes. Peritubal, periovarian and omental adhesions, tuboovarian (TO) masses, endometriotic deposits, fibroid, presence of fluid in the Pouch of Douglas or any pathology if present was noted. The patency of fallopian tubes was ascertained by injecting methylene blue into the uterine cavity and its spill through the fimbrial ends was checked. Statistical methods, the data obtained from the medical records was categorised as patients with primary and secondary infertility.

Statistical analysis was done by using descriptive statistical method for determining frequencies and percentages. Chi-square test was used for comparison of categorical variables. And independent t-test for comparing means. A p-value of $\leq 0.05$ was regarded as statistically significant and software used in the analysis were SPSS 17.0 version.

\section{RESULTS}

We studied 40 patients of female infertility comprising of 24 $(60 \%)$ cases of primary infertility and $16(40 \%)$ cases of secondary infertility. The mean age of presentation of patients with primary infertility was $29.5 \pm 3.5$ years as compared with $29 \pm 2.8$; years in those with secondary infertility.

The average age of active married life for the 40 patients with infertility was between 6 and 8 years, $5.6 \pm 2.4$ years for primary as compared with $5.5 \pm 3.5$ years for secondary ( $\mathrm{p}=$ 0.02) [Table 1].

In our study, the most commonly found pathologies were Polycystic Ovarian Disease (PCOD), endometriosis, tubal blockage and septate uterus. Of these, PCOD was detected in 9 (22.5\%) patients. These included $5(20.8 \%)$ patients with primary infertility and $4(25 \%)$ patients with secondary infertility. Simple ovarian cysts were found in $3(7 \%)$ of the patients, which included 1 (4\%) patient with primary infertility and $2(12 \%)$ patients with secondary infertility.

In our study, 7 (17.5\%) patients of primary infertility and $1(2.5 \%)$ patient of secondary infertility had tubal pathologies. These included tubal block in 5 (20.8), hydrosalpinx in 1 (4.1\%) and TO mass in $1(4.1 \%)$ in the primary infertility group. The subjects with secondary infertility had T0 mass in 1 (6.2\%).
Endometriosis was detected in 9 (22.5\%) patients, which included 5 (20.8\%) in primary infertility group and 4 (2.5\%) patients in secondary infertility group.

Uterine pathology was present in $9(22.5 \%)$ patients. These included submucous uterine fibroid 1 (4.1\%) and uterine septum in $5(20.8 \%)$ among the primary group. In patients with secondary infertility, 3 (18.75\%) had submucous fibroid [Table 2].

Based on the underlying pathology various therapeutic procedures were done in these patients, which included ovarian drilling in 9 patients with PCOD, cystectomy in two patients, adhesiolysis in patients with endometriosis and hysteroscopic myomectomy and septal resection was done in patients with respective uterine pathology [Table 3]. Some patients with primary infertility had more than one pathology and hence the total number of pathologies is more than the total number of patients evaluated [Table 2].

\begin{tabular}{|c|c|c|c|}
\hline & $\begin{array}{c}\text { Primary } \\
\text { Infertility }\end{array}$ & $\begin{array}{c}\text { Secondary } \\
\text { Infertility }\end{array}$ & P \\
\hline $\begin{array}{c}\text { Age at presentation } \\
\text { (years) }\end{array}$ & $29.5 \pm 3.5$ & $29 \pm 2.8$ & 0.37 \\
\hline Married of years & $5.6 \pm 2.4$ & $5.5 \pm 3.5$ & 0.02 \\
\hline \multicolumn{3}{|c}{ Table 1. Demographic Profile } \\
\hline
\end{tabular}

\begin{tabular}{|c|c|c|c|}
\hline Abnormality & $\begin{array}{c}\text { Primary } \\
\text { Infertility } \\
(\mathbf{n = 2 4 )} \mathbf{( \% )}\end{array}$ & $\begin{array}{c}\text { Secondary } \\
\text { Infertility } \\
(\mathbf{n = 1 6 )} \mathbf{( \% )}\end{array}$ & $\begin{array}{c}\text { Total } \\
(\mathbf{n = 4 0 )} \\
(\mathbf{\%})\end{array}$ \\
\hline Endometriosis & $5(20.8)$ & $4(25)$ & $9(22.5)$ \\
\hline $\begin{array}{c}\text { Submucosal } \\
\text { fibroid }\end{array}$ & $1(4.1)$ & $3(18.7)$ & $4(10)$ \\
\hline Septum uterus & $5(20.8)$ & 0 & $5(12.5)$ \\
\hline Tubal blockade & $5(20.8)$ & 0 & $5(12.5)$ \\
\hline Hydrosalpinx & $1(4.1)$ & 0 & $1(2.5)$ \\
\hline $\begin{array}{c}\text { Tubo-ovarian } \\
\text { mass }\end{array}$ & $1(4.1)$ & $1(6.2)$ & $2(5)$ \\
\hline Ovarian cyst & $1(4.1)$ & $2(12.4)$ & $3(7.5)$ \\
\hline $\begin{array}{c}\text { Polycystic } \\
\text { ovarian disease }\end{array}$ & $5(20.8)$ & $4(25)$ & $9(22.5)$ \\
\hline Grand Total & 24 (99.6) & 14 (84.6) & $\mathbf{3 8 ( 9 5 )}$ \\
\hline \multicolumn{4}{|c|}{ Table 2. Laparohysteroscopic Abnormalities } \\
Observed \\
\hline
\end{tabular}

\begin{tabular}{|c|c|c|c|}
\hline Procedure & $\begin{array}{c}\text { Primary } \\
\text { Infertility } \\
\text { (n= 24) (\%) }\end{array}$ & $\begin{array}{c}\text { Secondary } \\
\text { Infertility } \\
(\mathbf{n = 1 6 )} \mathbf{( \% )}\end{array}$ & $\begin{array}{c}\text { Total } \\
(\mathbf{n = 4 0 )} \\
(\mathbf{4})\end{array}$ \\
\hline Adhesiolysis & $6(25)$ & $5(31.25)$ & $11(27.5)$ \\
\hline Drilling & $5(28.8)$ & $4(25)$ & $9(22.5)$ \\
\hline Cystectomy & $2(8)$ & $6(37.5)$ & $8(20)$ \\
\hline Septal resection & $4(16.6)$ & 0 & $4(10)$ \\
\hline $\begin{array}{c}\text { Hysteroscopic } \\
\text { myomectomy }\end{array}$ & $1(4.1)$ & $3(18.7)$ & $4(10)$ \\
\hline Tubal cannulation & $5(20.8)$ & 0 & $5(12.5)$ \\
\hline Grand Total & $\mathbf{4}$ 23 & $\mathbf{1 8}$ & $\mathbf{4 1}$ \\
\hline \multicolumn{4}{|c|}{ Table 3. Procedure Done } \\
\hline
\end{tabular}

Eleven (27.5\%) patients were lost for follow-up. Among the remaining 29 subjects, $13(32.5 \%)$ conceived after hysterolaparoscopy and treatment. Of these patients six conceived spontaneously, two patients conceived after ovulation induction with intrauterine insemination and two patients conceived after in-vitro fertilization. 


\section{DISCUSSION}

The primary outcome in this study was conception rate, which was achieved at $32.5 \%$. Procedures were possible only in $72.5 \%$ of subjects $(60 \%$ of primary infertility and $40 \%$ with secondary infertility). Hence, it substantiates our hypothesis that infertility can be treated with a single diagnostic as well as therapeutic procedure like hysterolaparoscopy with a reasonable success rate. This is likely to improve with more effective techniques and experience. A follow-up study has been planned to further substantiate this hypothesis.

Polycystic ovarian disease is the most common endocrinopathies associated with anovulation in women of the reproductive age, affecting $16-33 \%$ of women.[2] Polycystic ovarian syndrome occurs in association with polycystic ovaries and amenorrhoea due to an ovulation, variable amounts of hirsutism and obesity is often accompanied by insulin resistance.

Endometriosis is also the most common cause observed in our study. The literature suggests that it can be the primary cause of infertility or one of the contributing factors. Endometriosis may induce infertility as a result of anatomic distortion and adhesions. Histologic examination should be done to confirm the presence of endometrial lesions, especially those with a non-classical appearance, but laparoscopy is the most commonly used modality to diagnose endometriosis. The golden rule in suspected patients with endometriosis is visual confirmation through laparoscopy (As mild endometriosis can only be detected on laparoscopy) before labelling a patient with endometriosis and starting treatment.[3]

The uterine pathology was seen in $22.5 \%$ of patients. Uterine pathologies are the cause of infertility in as many as $15 \%$ of couples seeking treatment $[4]$ and are diagnosed in as many as $50 \%$ of infertile patients.[5-7] Septate uterus was the intrauterine abnormality $(12.5 \%)$ in our study, which was undiagnosed by prior ultrasonography. Among all congenital uterine abnormalities, septate uterus is the most common cause associated with highest reproductive failure rates.[8,9] Although, a diagnosis of septate uterus per se is not an indication for septoplasty, the reproductive performance of women with an uncorrected septum is rather poor with most losses occurring

in

the first trimester (approximately 65\%). Pregnancy outcomes dramatically improved after surgical correction $(80 \%$ term delivery, $5 \%$ preterm delivery, $15 \%$ pregnancy loss). ${ }^{[8]}$

Dicker et al founded higher rates of abnormal findings in elderly women (above 40 years old). Abnormalities such as submucous myomas, endometrial hyperplasia and polyps were more frequent in this population, while in younger patients other uterine lesions such as adhesions and tubal ostia occlusion were more common.[10] When comparing hysteroscopic abnormalities before and after 38 years of age, Magos et al[11] did not show a significant difference (51\% of abnormal finding before 38 years and $43 \%$ after, $p=.38$ ). This result might be explained by the high rate of endometritis in their population (17.2\%), which was more frequently observed in younger woman.

Many studies describe the incidence of abnormal findings with hysteroscopy in infertile women or prior to IVF, but none give the proportion of these women who could benefit from an adapted treatment based on hysteroscopic findings.
It is difficult to draw direct connections between hysteroscopic findings and benefits from a specific treatment based on these findings. Treatments for some abnormalities are suspected beneficial in infertile women. These are intrauterine adhesions, congenital uterine malformations, endometrial polyps and uterine myomas.[12] Chronic endometrial inflammation and micropolyps have also been related to infertility and recurrent miscarriages.[13] Currently, the modern operative hysteroscopic techniques have made it a relatively easy and brief day care procedure with low morbidity and prompt recovery. Therefore, septal resection is recommended more liberally now-a-days.

\section{CONCLUSION}

This study thus clearly demonstrates the benefit of hysterolaparoscopy for the diagnosis and treatment in patients of primary and secondary infertility. We were able to achieve a higher conception rate of $32.5 \%$. Obviously, the operator must be adequately trained to use the laparo and hysteroscopic equipment and also to manage such patients.

\section{REFERENCES}

[1] Boivin J, Bunting L, Collins JA, et al. International estimates of infertility prevalence and treatmentseeking: potential need and demand for infertility medical care. Hum Reprod 2007;22(6):1506-12.

[2] McVeigh E. Polycystic ovarian syndrome. In: Baker PN, Leusley DM, eds. Obstetrics and Gynaecology: an evidence based text for MROCG. London: Oxford University Press 2004: p. 588-93.

[3] Aleem M, Bashir A. Endometriosis in diagnostic laparoscopy Specialist Pak J Med Sci 1995;11(2):1037.

[4] Wallach EE. The uterine factor in infertility. Fertil Steril 1972;23(2):138-58.

[5] Brown SE, Coddington CC, Schnorr J, et al. Evaluation of outpatient hysteroscopy, saline infusion hysterosonography and hysterosalpingography in infertile women: a prospective, randomized study. Fertil Steril 2000;74(5):1029-34.

[6] Romano F, Cicinelli E, Anastasio PS, et al. Sonohysterography versus hysteroscopy for diagnosing endouterine abnormalities in fertile women. Int J Gynaecol Obstet 1994;45(3):253-60.

[7] Mooney SB, Milki AA. Effect of hysteroscopy performed in the cycle preceding controlled ovarian hyperstimulation on the outcome of in vitro fertilization. Fertil Steril 2003;79(3):637-8.

[8] Homer HA, Li TC, Cooke ID. The septate uterus: a review of management and reproductive outcome. Fertil Steril 2000;73(1):1-14.

[9] Grimbizis GF, Camus M, Tarlatzis BC, et al. Clinical implications of uterine malformations and hysteroscopic treatment results. Hum Reprod Update 2001;7(2):161-74.

[10] Dicker D, Goldman JA, Ashkenazi J, et al. The value of hysteroscopy in elderly women prior to in vitro fertilization-embryo transfer (IVF-ET): a comparative study. Journal of In Vitro Fertilization and Embryo Transfer 1990;7(5):267-70.

[11] Magos A, Al-Khouri A, Scott P, et al. One stop fertility clinic. Journal of Obstetrics and Gynaecology 2005;25(2):153-9. 


\section{Jemds.com}

[12] Sanders B. Uterine factors and infertility. The Journal of Reproductive Medicine 2006;51(3):169-76.
Original Research Article

[13] Frydman R, Belaisch-Allart JC. Results of in vitro fertilization for endometriosis. Contributions to Gynecology and Obstetrics 1987;16:328-31. 